\title{
Análise de propriedades de chapas de aço SAE 1020 laminadas a quente e a frio
}

\author{
Property analysis of hot and cold-rolled SAE 1020 steel sheets
}

Gabrielle Schutz Braz; Gabriel Inácio Pontin ${ }^{1}$

${ }^{1}$ Centro Universitário da Fundação Educacional de Barretos, Unifeb, Barretos, São Paulo

\begin{abstract}
Resumo
O avanço da ciência e o surgimento de novas tecnologias referentes à utilização de materiais metálicos tornam imprescindível a busca por novos conhecimentos na área. O estudo teve como objetivo avaliar a influência da temperatura no processo de laminação sobre as propriedades mecânicas do aço SAE 1020. Para tanto, foram utilizados ensaios mecânicos de dureza e de tração, além de análises metalográficas. Como consequência, obteve-se o comportamento do material, quando sujeito a esforços mecânicos, sendo possível analisar as características dos metais a partir dos referidos ensaios mecânicos e metalográficos, caracterizando-se de suma importância para a determinação do melhor processo pelo qual a chapa deverá passar e da melhor aplicação de cada material processado. Portanto, a temperatura usada durante o processo de laminação afeta consideravelmente o produto final, tornando-o usual para aplicações de acordo com os requisitos das propriedades nos projetos envolvendo os materiais.
\end{abstract}

Palavras-chave: Dureza; Laminação; Metalografia; Tração.

\begin{abstract}
With the advancement of science and the emergence of new technologies related to the use of metallic materials, it is essential to search for new knowledge in the area. This study aimed to evaluate the influence of temperature in the rolling process on the mechanical properties of SAE 1020 steel. For this purpose, mechanical tests of hardness and tensile strength, in addition to metallographic analyzes, were performed. Consequently, the behavior of the material was obtained, when subjected to mechanical efforts, being possible to analyze the characteristics of the metals from the referred mechanical and metallographic tests, which is extremely important for the determination of the best process by which the plate should pass and the best application of each processed material. Therefore, the temperature used during the lamination process considerably affects the final product, making it usual for applications according to the requirements of the properties in the projects involving the materials.
\end{abstract}

Keywords: Hardness; Lamination; Metallography; Traction.

Autor correspondência: Gabrielle Schultz Braz, Rua Ari Jorge Fonseca Ramos, 104, Parque Independência, Barra Mansa, RJ, Brasil, CEP:27325-110, email: gabischultzbraz@gmail.com

Recebido para publicação: 11/12/2019

Aceito para publicação: 29/03/2021

https://doi.org/10.4322/1980-0029.032019 


\section{Introdução}

Segundo Coradin (2017), o aço é um componente importante desde quando sua extração era a partir de meteoritos até atingir a etapa de refino. Atualmente tem se destacado por ser um material $100 \%$ reciclável, sendo que, por suas características, é reaproveitado para a transformar-se em outros produtos, tornando o processo produtivo mais sustentável, deixando claro sua importância para a indústria, comércio e meio ambiente.

A partir de Araújo (1997), o aço passou a ser fabricado de diversas formas, o que leva a um imenso desenvolvimento, aumentando a industrialização e gerando empregos. Isso ocorre desde as forjas catalãs até os conversores Linz Donawitz (LD), onde ocorre o refino do ferro-gusa, ou seja, a formação do aço, sendo que a partir daí são fabricados os lingotes e, posteriormente, as chapas.

A partir das lingoteiras, vem o processo de laminação, que é quando, através da força de atrito entre rolos e chapas, essas chapas vão se deformando, normalmente diminuindo sua espessura e assim aumentando seu comprimento. Esse processo pode ser realizado tanto a quente, que é quando necessitamos de uma grande deformação nas chapas, quanto a frio, que é quando necessitamos de acabamento superficial (Araújo, 1997).

De acordo com Garcia et al. (2012), mediante essa diferença de temperatura de trabalho, as propriedades do aço podem ser modificadas, o que nos leva a pensar no grau dessa mudança. Para verificar tais propriedades, realizam-se ensaios mecânicos, tais como tração, que consiste em, através de garras, esticar o material até que se rompa, obtendo valores de limite de escoamento, limite de resistência à tração, entre outros.
Há também o ensaio de dureza, que consiste tanto em riscar quanto em penetrar o material para determinar a carga que ele suporta até deformar; e o ensaio de metalografia, que consiste em realizar ataques químicos para verificar a estrutura do material, ou seja, seus grãos, contorno de grãos, entre outros. A partir das análises das propriedades mecânicas e microestruturais, podemos observar as principais vantagens e desvantagens da temperatura no aço SAE 1020, definindo desse modo qual a sua melhor utilização (Garcia et al., 2012).

Assim, este estudo foi desenvolvido para determinar a influência da temperatura durante a laminação das chapas, neste caso, diferenciando processo a quente e a frio nas propriedades mecânicas do aço SAE 1020, para verificar a influência, a partir da utilização dos ensaios de tração, dureza e de metalografia, quais parâmetros foram alterados e analisar seus comportamentos.

\section{Material e Métodos}

\section{Ensaio de Tração}

Para determinar as propriedades, foram utilizadas 20 chapas finas aço SAE 1020 (aço de baixo carbono $(0,20 \%))$, tipo 14 laminadas a quente e a frio, com 2 e $1,9 \mathrm{~mm}$ de espessura, respectivamente, tendo seu dimensionamento feito através da ABNT NBR ISO 6892 (Associação Brasileira de Normas Técnicas, 2013) (Figura 1). Tais chapas, após usinadas, foram encaminhadas para o ensaio de tração, sem nenhum tratamento térmico ou de superfície adicional (Figura 2).

Para o ensaio de tração, foi utilizada a máquina universal WDW-100e, marca SHIGIN ${ }^{\circ}$, conectada por meio de sensores a um microcomputador
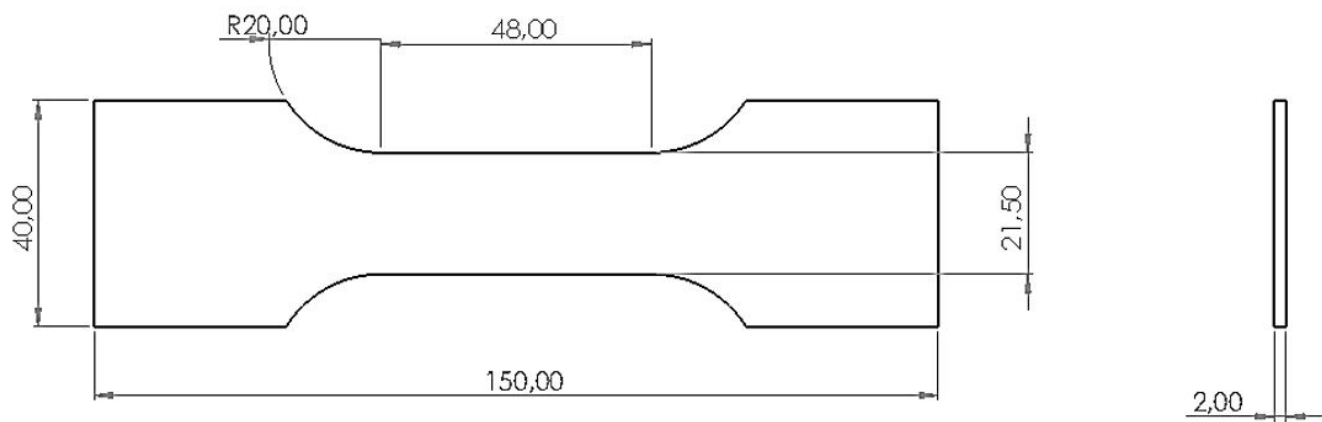

Figura 1. Dimensões do corpo de prova. 


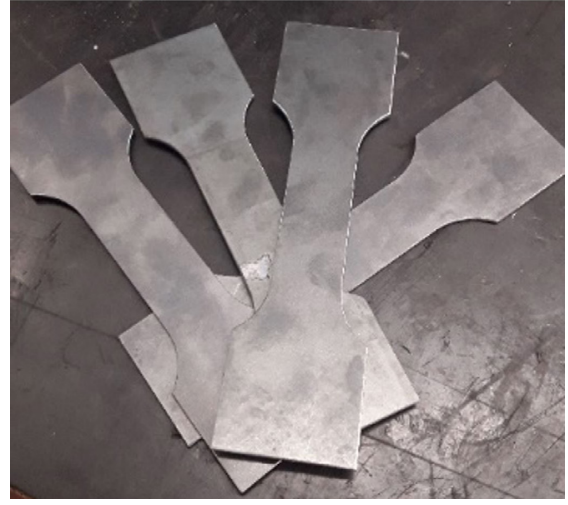

Figura 2. Corpos de prova após usinagem.

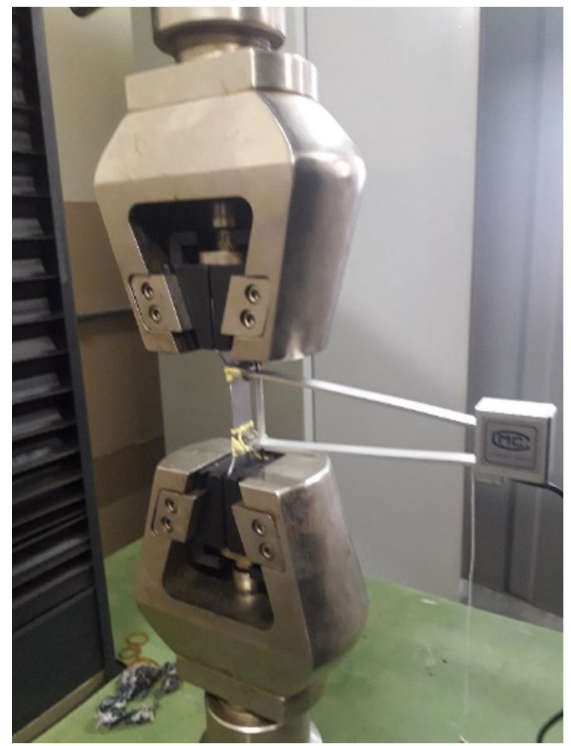

Figura 3. Ensaio sendo realizado na máquina de tração. responsável por gerar o gráfico tensão e deformação, com capacidade de carga de $100 \mathrm{kN}$ e velocidade de operação de $5,0 \mathrm{~mm} \mathrm{~min}{ }^{-1} \mathrm{com}$ auxílio do extensômetro (Figura 3). Os ensaios foram realizados em temperatura de $30^{\circ} \mathrm{C}$, onde foram determinados os parâmetros de área de seção retangular, comprimento, espessura.

Foram realizados primeiramente ensaios nas 10 chapas laminadas a quente e, logo após, nas 10 chapas laminadas a frio, obtendo-se os valores de força máxima, tensão de resistência, limite de escoamento, alongamento total, estricção e módulo de elasticidade para que possam ser comparados com a teoria. Usou-se um paquímetro universal de medição externa $(0 \sim 25 \mathrm{~mm})$, para dimensionar a amostra, antes e após o ensaio, cujos valores foram usados nos cálculos referentes às propriedades mecânicas do material.

\section{Ensaio Metalográfico}

Para realizar a análise metalográfica macrográfica, fez-se o corte do corpo de prova do aço SAE 1020. Em seguida, adicionou-se a amostra ao molde com resina, onde ficou durante 72 horas para secagem. Após a secagem, a peça foi lixada à mão com lixas d'água nas seguintes granulometrias: $120,220,320,600,1200$ e 1500 mesh, lixando até restarem somente os riscos da última lixa utilizada (Figura 4).

Usando a máquina Politriz, modelo DP-10 - marca Struers, fez-se o polimento da amostra. Para tanto, ajustou-se a vazão da água, adicionou-se o abrasivo alumina; e, segurou-se levemente a peça sobre o pano de polimento com as duas mãos até que a

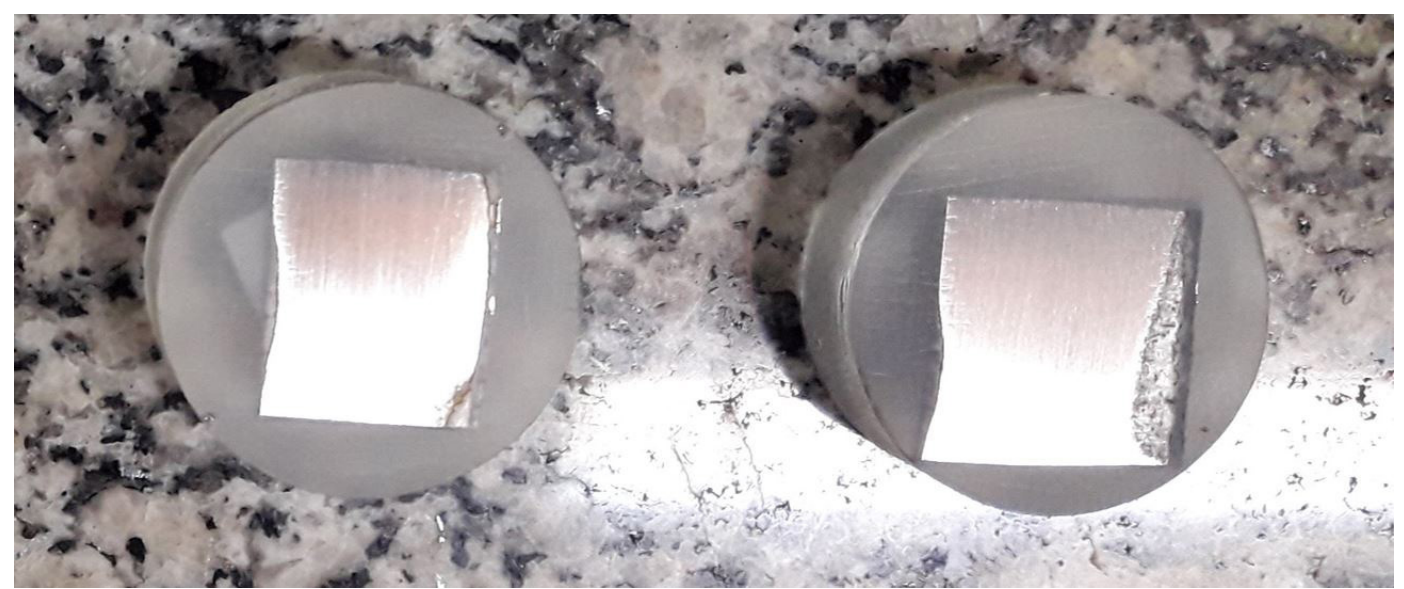

Figura 4. Amostras após lixadas. 
superfície ficasse sem nenhum tipo de ranhura. Para que pudesse ser analisada microscopicamente, fez-se o ataque químico da amostra, utilizando-se Nital a 2\% (2\% de ácido Nítrico e 98\% de álcool etílico). Após o ataque químico, limpou-se a amostra, para remover os resíduos do processo, através da lavagem com água e álcool, sendo, em seguida, feito o processo de secagem por jato de ar quente, proveniente de um secador.

Com a amostra devidamente preparada, pôde-se realizar a análise macroscópica, por meio do microscópio modelo Stereo Discovery. V8 - marca ZEISS com resolução da lente de 20x (Figura 5A). Para realizar a análise metalográfica micrográfica, foram seguidas as etapas do processo de análise metalográfica macrográfica, descritos acima, diferenciando-se o microscópio utilizado modelo TNM 07T PL - marca OPTON (Figura 5B).

\section{Ensaio de Dureza}

Para determinar as propriedades através do ensaio de dureza, foram utilizadas 2 chapas finas aço SAE 1020 após ensaio de tração, sendo que, para se atingir um bom resultado, foram realizadas 15 coletas de dados por amostra, totalizando
30 ensaios. Sendo a classificação realizada pela divisão através do tipo de processo de laminação.

Para a efetuação do ensaio, utilizou-se um durômetro da marca Pantec, de precisão, e escolhida a modalidade Rockwell para interpretação das medidas convencionadas à norma ABNT NBR ISO 6508 (Associação Brasileira de Normas Técnicas, 2019). De acordo com as características e aplicações do material em estudo, selecionou-se a escala B com um penetrador do tipo esfera de $1,59 \mathrm{~mm}$ (1/16") e uma carga para aplicação de 100 kgf; sendo que esta configuração é utilizada para aços não temperados, ferros fundidos e algumas ligas não ferrosas.

As etapas para realização do ensaio após a calibração do equipamento foram seguidas de acordo com a Figura 6 a fim de identificar diferenças entre os tipos de laminação.

\section{Resultados e Discussão}

Com a realização do ensaio de tração, montaram-se as Tabelas 1 e 2 que demonstram os valores fornecidos pela máquina de ensaio para o microcomputador, que respectivamente referem-se às chapas laminadas a quente $\mathrm{e}$ a frio.

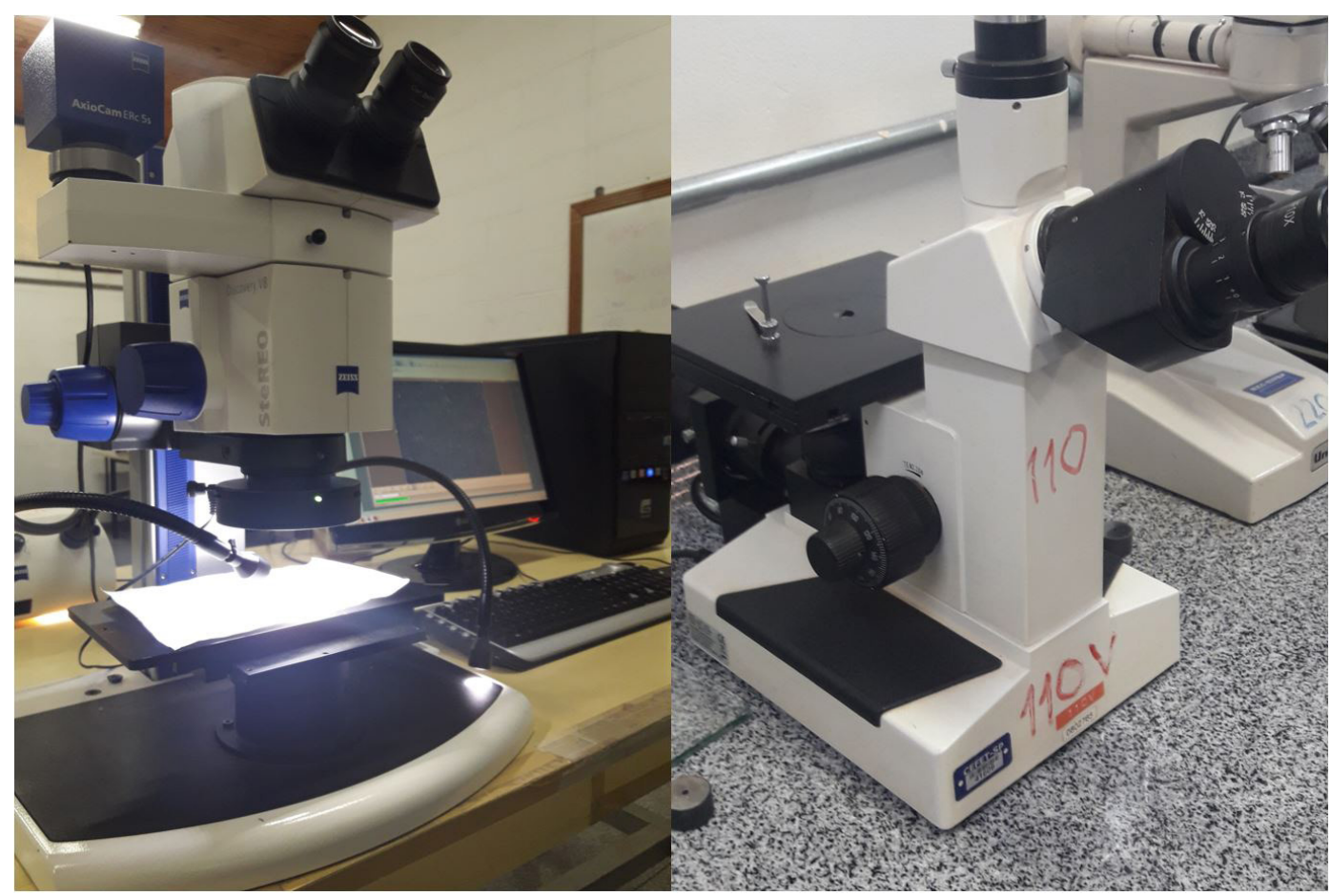

Figura 5. A. Análise Macroscópica. B) Análise Microscópica. 


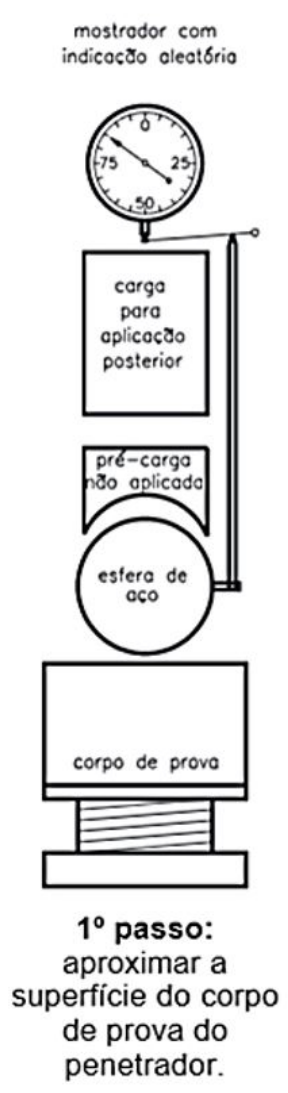

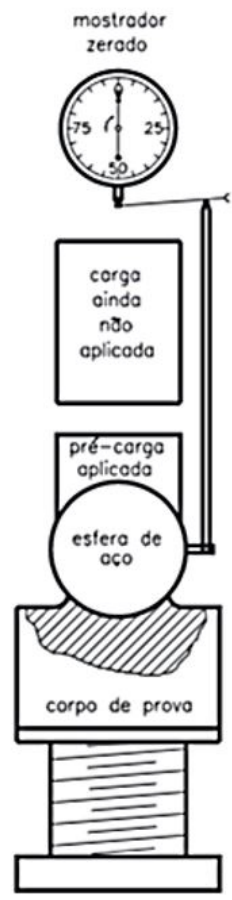

$2^{\circ}$ passo: submeter o corpo de prova a uma précarga (carga menor).

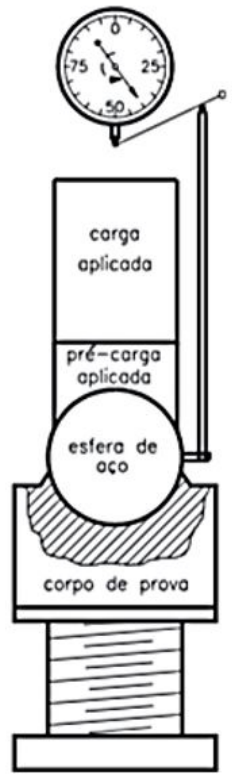

$3^{\circ}$ passo:

aplicar a carga maior até o ponteiro parar.

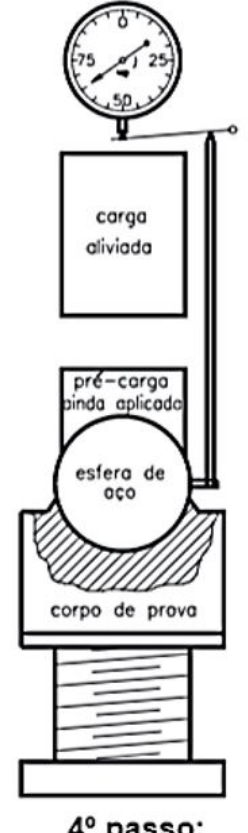

retirar a carga maior e fazer a leitura do valor indicado no mostrador, na escala apropriada.

Figura 6. Etapas da realização do ensaio.

Tabela 1. Dados do ensaio das chapas laminadas a frio.

\begin{tabular}{cccccc}
\hline Amostra & $\begin{array}{c}\text { Força Máxima } \\
(\mathbf{k N})\end{array}$ & $\begin{array}{c}\text { Tensão de } \\
\text { Resistência } \\
(\mathbf{M P a})\end{array}$ & $\begin{array}{c}\text { Limite de } \\
\text { Escoamento } \\
(\mathbf{M P a})\end{array}$ & $\begin{array}{c}\text { Alongamento } \\
\text { Total (\%) }\end{array}$ & Estrição (\%) \\
\hline 1 & 17.09 & 397.50 & 330.53 & 39.19 & 49.52 \\
2 & 16.90 & 393.05 & 327.09 & 33.73 & 43.35 \\
3 & 16.96 & 394.38 & 344.86 & 36.76 & 41.98 \\
4 & 16.36 & 380.36 & 312.63 & 37.03 & 51.19 \\
5 & 17.00 & 395.33 & 339.51 & 39.19 & 51.50 \\
6 & 16.39 & 381.06 & 323.56 & 35.73 & 45.27 \\
7 & 16.56 & 385.18 & 330.07 & 34.38 & 49.08 \\
8 & 16.16 & 375.93 & 309.63 & 39.68 & 49.70 \\
9 & 17.06 & 396.84 & 355.00 & 37.30 & 43.80 \\
10 & 17.00 & 395.40 & 345.49 & 37.30 & 48.76 \\
Média & 16.75 & 389.50 & 331.84 & 37.03 & 47.42 \\
Desvio Padrão & 0.33 & 7.62 & 13.82 & 1.90 & 3.30 \\
\hline
\end{tabular}

As curvas obtidas no ensaio de tração mostram todos os patamares até o ponto onde ocorreu a ruptura, tornando possível verificar que a tensão última do material aço SAE 1020 é de
$397,50 \pm 10 \% \mathrm{MPa}$. Conclui-se, portanto, que o valor obtido está dentro dos padrões esperados quando comparado com valores teóricos em que a tensão última do material aço SAE 1020 é de 
$420 \mathrm{MPa}$, independentemente do processo de conformação.

De acordo com Teixeira \& Assis (2017) e o ensaio de tração no aço AISI 1020 soldado com eletrodo revestido 6013, é possível verificar que a tensão última do material soldado, aço AISI 1020, é de $375,36 \mathrm{MPa}$. O valor obtido, quando comparado com valores teóricos em que a tensão última do aço AISI 1020 é de $420 \mathrm{MPa}$, conclui-se que este está dentro dos padrões esperados. O fato de o aço AISI 1020 ter se rompido antes que a solda se rompesse mostra que a tensão última da solda é maior que a do material. Isto comprova que a tensão última da solda está de acordo com os valores teóricos encontrados, que é de $427 \mathrm{MPa}$.

Com elas, foram criados os gráficos de curva Tensão x Deformação (Figuras 7A e 7B), que representam as chapas laminadas a quente e as chapas laminadas a frio.
Como pode-se observar, os gráficos das Figuras 7A e 7B apresentam comportamentos semelhantes, diferenciando-se numericamente em cada amostra. Verificando-se com isto que as medições da força e do alongamento obtidos nas tabelas de dados resultam em valores satisfatórios, para interpretar visualmente o tamanho final das amostras.

No ensaio metalográfico, percebe-se que, dependendo de como as etapas da micrografia são feitas, obtém-se um resultado diferente. A partir da leitura do material de Colpaert (2008), de onde a Figura 8 é proveniente, determina-se que as amostras em que a proporção de fases escuras (perlita) e claras (ferrita) é de aproximadamente $25 \%$ para $75 \%$, que corresponde à proporção do aço SAE 1020.

No resultado da macroscopia com zoom de 20x, percebe-se que as fases de cor escura (carbono)

Tabela 2. Dados das chapas laminadas a quente.

\begin{tabular}{cccccc}
\hline Amostra & $\begin{array}{c}\text { Força Máxima } \\
(\mathbf{k N})\end{array}$ & $\begin{array}{c}\text { Tensão de } \\
\text { Resistência } \\
(\mathbf{M P a})\end{array}$ & $\begin{array}{c}\text { Limite de } \\
\text { Escoamento } \\
\mathbf{( M P a )}\end{array}$ & $\begin{array}{c}\text { Alongamento } \\
\text { Total (\%) }\end{array}$ & Estricção (\%) \\
\hline 1 & 13.86 & 339.34 & 276.08 & 43.51 & 48.52 \\
2 & 13.88 & 339.85 & 271.30 & 43.78 & 58.52 \\
3 & 13.85 & 339.08 & 272.99 & 44.32 & 51.68 \\
4 & 13.86 & 339.24 & 274.15 & 44.86 & 58.82 \\
5 & 13.84 & 338.89 & 259.41 & 44.86 & 65.14 \\
6 & 13.86 & 339.31 & 272.96 & 44.65 & 48.15 \\
7 & 13.86 & 339.23 & 271.95 & 43.24 & 48.52 \\
8 & 13.85 & 339.05 & 276.29 & 44.05 & 49.55 \\
9 & 13.86 & 339.25 & 274.85 & 44.32 & 55.45 \\
10 & 13.85 & 339.05 & 272.77 & 44.32 & 52.02 \\
Média & 13.86 & 339.23 & 272.28 & 44.19 & 53.64 \\
\hline
\end{tabular}
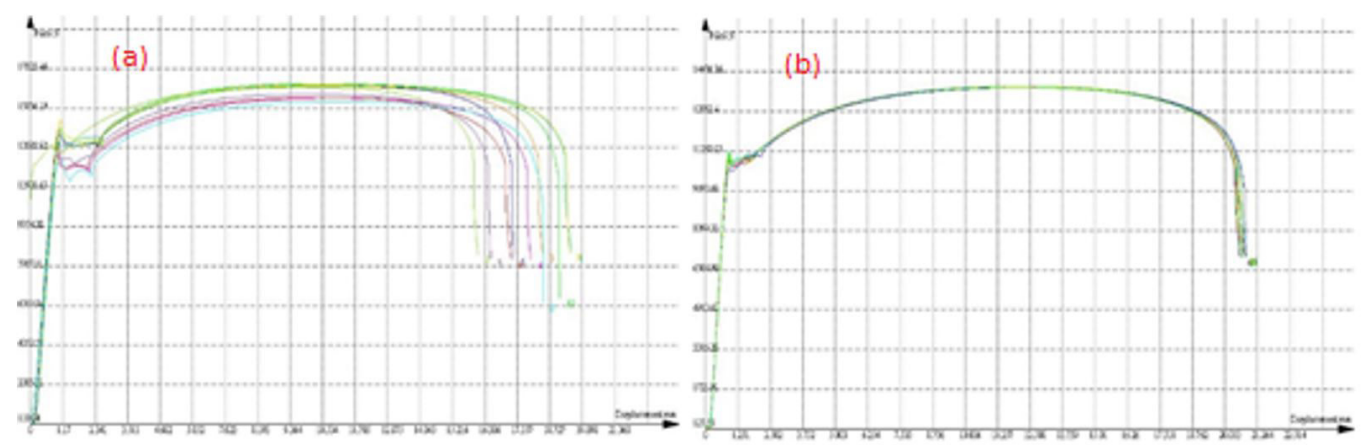

Figura 7. A) Laminadas a Frio. B) Laminadas a Quente. 
aparecem em menor tamanho. Na Figura 9B, consegue-se visualizar os contornos de grão, com linhas finas formando figuras disformes. Já na Figura 9A, tais linhas não podem ser vistas com clareza, demonstrando que a amostra não foi atacada de forma correta. Para resolver este problema, a amostra deveria ser atacada quimicamente por um tempo superior.

Na microscopia com zoom de 100x, visualizouse a diferença da distribuição dos grãos entre a chapa fria e a chapa quente, como mostram as Figuras 10A e 10B, sendo possível perceber que, na chapa laminada a quente, o fato de os grãos terem crescido acarreta uma concentração dos componentes (ferro e carbono).

Na Figura 11, os contornos de grãos são pouco visualizados devido ao processo de preparação das amostras. Mas, se relacionarmos as Figuras 9(A e B) e 10(A e B), percebemos que, nas chapas que foram laminadas a quente, consegue-se ver claramente as linhas dos contornos de grão, devido à temperatura da chapa e pelo fato de a chapa, quando laminada a frio, tender ao encruamento, ou seja, ficam mais duras e

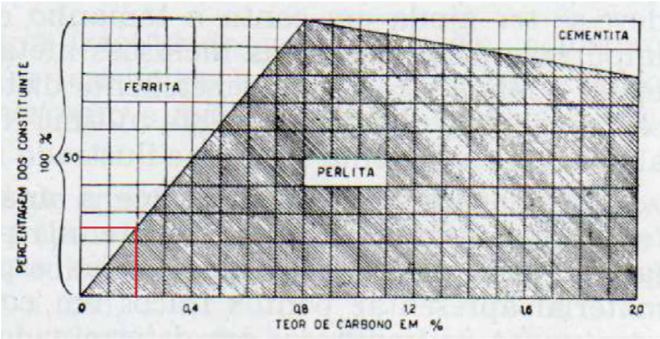

Figura 8. Gráfico de Concentração de Constituintes por Teor de Carbono (Colpaert, 2008). resistentes à medida que sofrem deformação durante a laminação.

Como hipótese, tem-se a sugestão de uma liga hipoeutetóide, visto que se formou com aproximadamente $0,2 \%$ de carbono, estando à esquerda do ponto eutetóide $(0,77 \% \mathrm{C})$, no diagrama de fases. Para a formação do aço, geralmente é utilizado um resfriamento lento, no qual observase a nucleação da ferrita nos contornos de grão da austenita.

No estudo de Leite et al. (2017), vimos que, a partir da análise metalográfica, constatou-se que a composição da amostra é composta por cementita $3 \%$ e ferrita $97 \%$. Sendo assim, praticamente todo o carbono presente no aço 1020 está na forma de cementita (Fe3C - 6,67\% $+93,33 \% \mathrm{Fe})$, apesar de representar somente $3 \%$ do volume, e o restante está junto à ferrita.

Após a realização do ensaio nas partes da chapa em que não houve deformação nem foi afetada pela garra da máquina de tração, buscou-se verificar a diferença da maleabilidade do aço através do ensaio de dureza e chegou-se aos valores descritos na Tabela 3.

Com o resultado da média, chega-se ao fato de que ambas as chapas ficaram entre os limites de 20 e 80 HBR descritos pela norma, como mostra a Tabela 3 e Figura 12A. Percebe-se que o processo de laminação a frio, além de dar acabamento superficial e aumentar a dureza do material, é totalmente inverso ao processo de laminação a quente. No gráfico da Figura 12B, percebemos claramente que a variação de uma chapa para outra é pequena, sendo que o último ponto é bem próximo. Mas, se a comparação for em relação à média, percebemos que essa variação
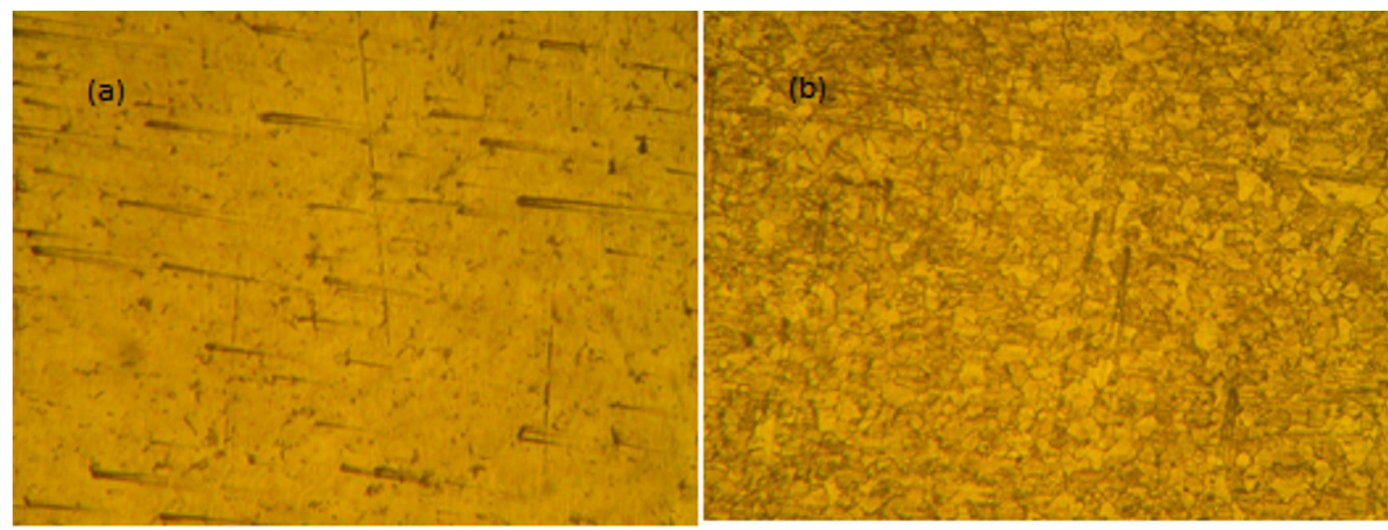

Figura 9. A) Laminada a Frio. B) Laminada a Quente. 


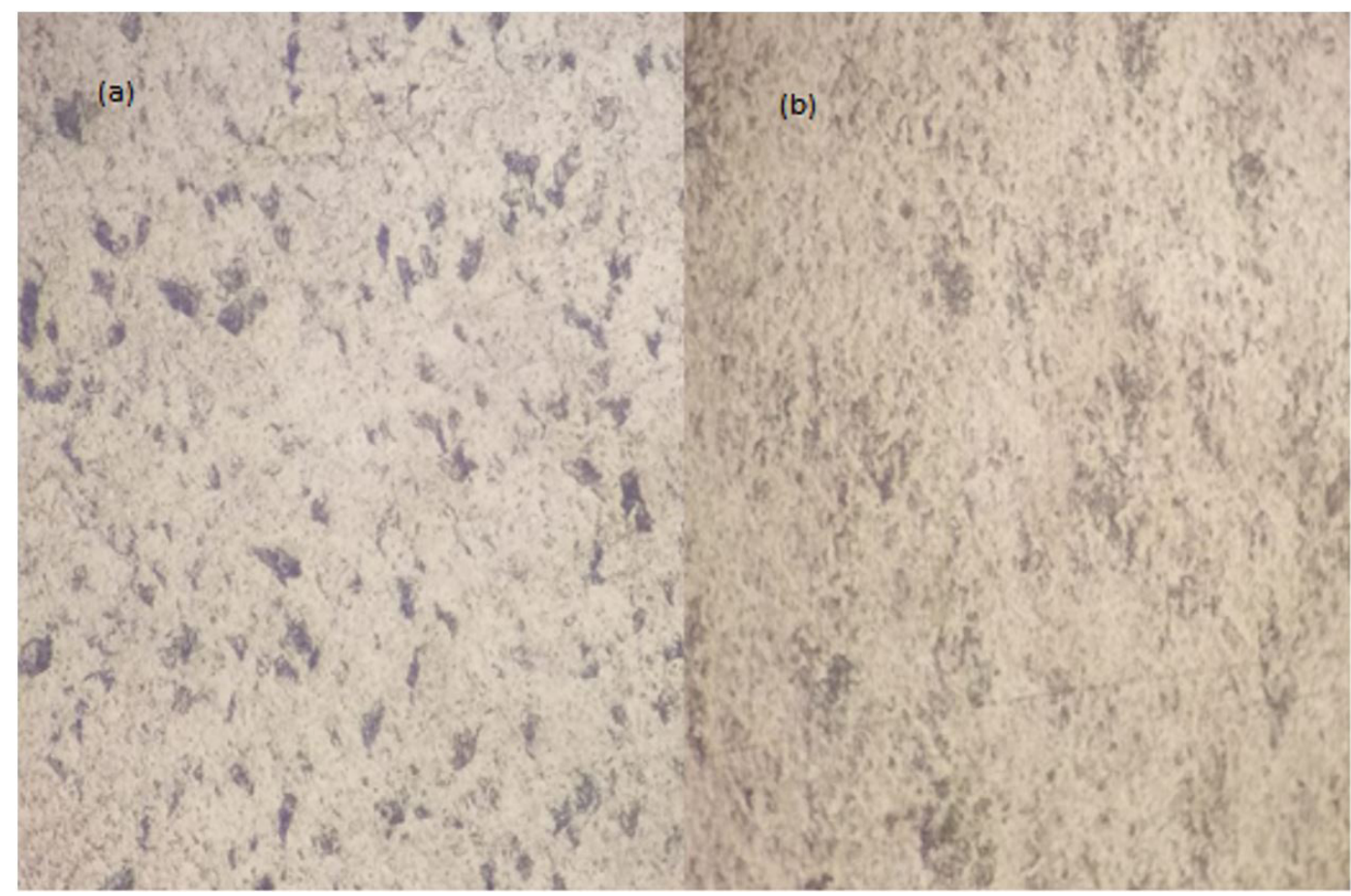

Figura 10. A) Chapa laminada a Quente. B) Chapa Laminada a Frio.

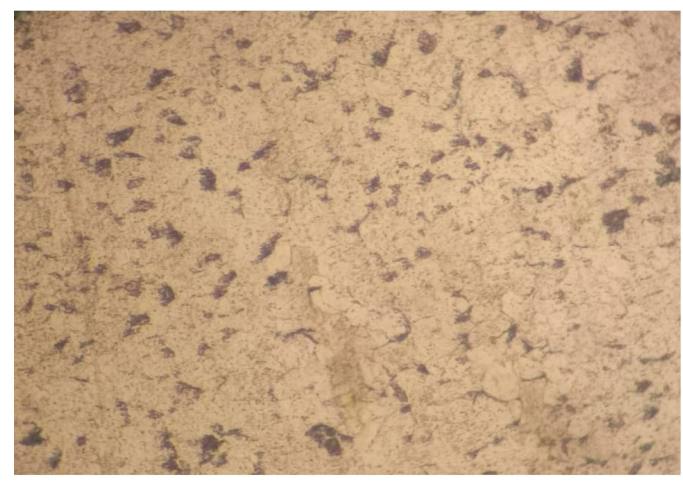

Figura 11. Microscopia da Chapa laminada a Quente, zoom 100x (diminuição da luz).

se torna alta, devido à forma como foi realizado o processo de conformação, a microestrutura do material, entre outras variações relacionadas ao processo de fabricação das chapas.

Portanto, mesmo com essas variações, o produto que utilizar essas chapas dependerá da escolha do processo de fabricação, sendo as chapas laminadas a quente destinadas a produtos como tubos metálicos, rodas, autopeças, entre outros; já as chapas laminadas a frio, destinadas
Tabela 3. Resultados Ensaio de Dureza.

\begin{tabular}{ccc}
\hline & $\begin{array}{c}\text { Chapa } \\
\text { Laminada a } \\
\text { Quente }\end{array}$ & $\begin{array}{c}\text { Chapa } \\
\text { Laminada a } \\
\text { Frio }\end{array}$ \\
\hline $\begin{array}{c}\text { Pontos nas } \\
\text { Amostras }\end{array}$ & Dureza (HRB) & Dureza (HRB) \\
\hline 1 & 33 & 45,5 \\
2 & 29 & 41 \\
3 & 28 & 47 \\
4 & 23 & 43,5 \\
5 & 23 & 44 \\
6 & 24,5 & 48,5 \\
7 & 25,5 & 39,5 \\
8 & 26 & 39,5 \\
9 & 28 & 36,5 \\
10 & 25,5 & 38 \\
11 & 25 & 38,5 \\
12 & 24,5 & 37 \\
13 & 33 & 39 \\
14 & 27 & 33 \\
15 & 30,5 & 31 \\
Média & 27,03 & 40,1 \\
Desvio Padrão & 3,21 & 4,93 \\
\hline & &
\end{tabular}

para eletrodomésticos, automóveis, esquadrias, entre outros. 

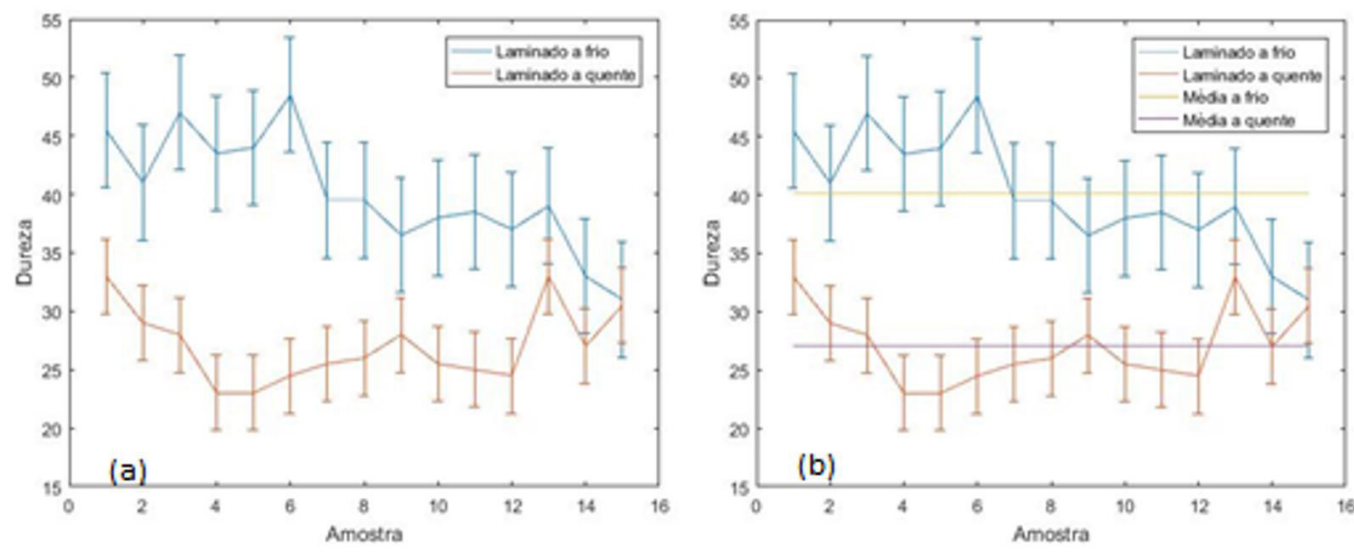

Figura 12. A) Desvio da Dureza. B) Média das Durezas.

\section{Conclusão}

Mediante análise dos resultados atingidos a partir da realização dos ensaios mecânicos e macroestrutural, conclui-se que a temperatura durante o processo de laminação das chapas altera algumas propriedades mecânicas do material, tais como: o limite de escoamento, a tensão de resistência, dureza, ainda que outras variáveis possam ser utilizadas para se obter um melhor resultado referente aos ensaios, como a utilização de tratamentos térmicos, outros ensaios, entre outros aspectos.

\section{Referências}

Araújo, L. A. (1997). Manual de Siderurgia (Vol. 1). São Paulo: Editora Arte \& Ciência.

Associação Brasileira de Normas Técnicas ABNT. (2019). NBR ISO 6508-1:2019: Materiais metálicos - Ensaio de dureza Rockwell Parte 1: Método de ensaio. Rio de Janeiro: ABNT.

Associação Brasileira de Normas Técnicas - ABNT. (2002). NBR NM 6892: Materiais Metálicos -
Ensaio de tração a temperatura ambiente. Rio de Janeiro: ABNT.

Colpaert, H. (2008). Metalografia dos produtos comuns (4a ed., Revista e atualizada por Costa e Silva, A. L. V.). São Paulo: Editora Blucher.

Coradin. (2017, Junho 20). O aço é 100\% reciclável. Recuperado em 22 de outubro de 2019, de https:// www.ferrovelhocoradin.com.br/aco-reciclavel/

Leite, S. S., Datres, K. D. L., Fernandes, L. L., Machado Junior, J. C., Damian, J. S. M., Pires, G. B., Scarpin, L. M., \& Santos, P. S. B. (2017). Ensaio de Tração e Metalografia do Aço SAE 1020. Revista Engenharia em Ação UniToledo, 2(1), 70-82.

Garcia, A., Spim, J. A., \& Santos, C. A. (2012). Ensaio dos Materiais (2. ed.). Rio de Janeiro: LTC.

Teixeira, A. D. R., \& Assis, A. F. (2017). Análise do Ensaio de Tração em Chapas de Aço 1020 Soldadas por Eletrodo Revestido. Eu, a Indústria e o Mundo, 3(1), 1-3. Recuperado em 22 de abril de 2021, de https://www.locus.ufv.br/ bitstream/123456789/14241/1/201-1253-1-PB.pdf 